\title{
REDES SOCIAIS: POSSIBILIDADES EXPANDIDAS PARA A EDUCAÇÃO?
}

\author{
Social networks: expanded possibilities for education?
}

Redes sociales: la ampliación de oportunidades para la educación?

\author{
Mauro Meirelles \\ Professor na Unisalles - Canoas \\ mauromeirelles@icloud.com \\ César Steffen \\ Professor na Unisalles - Canoas \\ cesar@steffen.net.br
}

\section{Resumo}

Este artigo busca pensar e avaliar o impacto e a onipresença das redes sociais na sociedade brasileira para, a partir disso, explorar algumas possibilidades que estas têm a oferecer como um lócus ampliado de aprendizagem e interação entre alunos e professores. Objetiva estabelecer um retrato da educação à distância no Brasil e pensar como, estas redes, podem servir a educação tanto presencial como a distância no que tange as suas possibilidades educativas.

Palavras-chave: Redes Sociais. Educação. Facebook.

\begin{abstract}
This paper aims think and evaluate the impact and the social ubiquity networks in Brazilian society, from there, explore some of its possibilities to offer, as a locus of enhanced learning and interaction between students and teachers. Aims establishing a overview at distance education in Brazil and think how these networks can serve classroom and distance education in terms of educational possibilities.
\end{abstract}

Keywords: Social Networks. Education. Facebook.

\section{Resumen}

En este artículo se pretende reflexionar y evaluar el impacto y la ubicuidad de las redes sociales en la sociedad brasileña y, a partir de ahí, explorar algunas posibilidades que tienen para ofrecer como un locus ampliado del aprendizaje y la interacción entre los estudiantes y los profesores. Tiene como objetivo establecer una imagen de la educación a distancia en Brasil y pensar cómo estas redes pueden servir tanto como aula de educación presencial como a la distancia con respecto a sus posibilidades educativas.

Palabras clave: Redes Sociales. Educación. Facebook. 


\section{INTRODUÇÃO}

No momento em que redigimos este texto ${ }^{1}$, em algum lugar do Brasil, encontram-se alguns milhares de brasileiros que estão recebendo educação e treinamento através de sistemas de interação e educação EAD via Internet. Mesmo parecendo pequeno esse número em relação a população total do país, e se levando em conta o tempo relativamente curto de surgimento, desenvolvimento e regulamentação da EAD via Internet, podemos observar que, esta tecnologia, teve um forte impacto no contexto educacional.

Exemplar disso é o Exame Nacional de Desempenho de Estudantes (ENADE), exame que verifica o desempenho de estudantes de ensino superior que, em 2009, mostrou que os educandos de EAD tiveram desempenho melhor nas provas do que os educandos de cursos presenciais em 7 áreas de 13 comparadas. Em cursos como Administração, Ciências Sociais e Turismo a diferença das notas chega a mais de 10 pontos. Apesar do ENADE não ser um medidor exato e preciso dos resultados e do impacto da EAD, principalmente por ainda comparar poucos cursos. Observa-se, a partir disto o potencial impacto que este suporte pode ter no contexto educacional brasileiro.

Um breve resgate histórico nos mostra que, por mais que hoje desponte como uma novidade aliada as novas tecnologias, a história da Educação a Distância remonta ao ano de 1840, com a criação da Faculdade Sir Isaac Pitman. Esta, a primeira escola por correspondência na Europa. Aliás, o velho continente mostra ampla tradição de ensino nãopresencial com cursos de idiomas por correspondência, realizados na Alemanha no ano de 1856. Os Estados Unidos também se mostram pioneiros investidores no formato, onde, em 1873 na cidade de Boston, criou-se a Society to Encourage Study at Home (SH).

Isto posto, é basilar que, antes de irmos adiante em nosso argumento, diferenciemos o que se denomina educação aberta e educação à distância. A educação aberta está ligada a experiências em educação não-presencial, por correspondência, etc., e têm como mote possibilitar o acesso ao ensino superior a pessoas sem a necessária formação para ingresso ao mesmo. Ou seja, o termo aberta significava, antes de tudo, uma proposta sócio-política de democratização de acesso ao ensino as várias camadas da população, modelo de ensino no qual a Open University é, hoje, o maior exemplo.

\footnotetext{
${ }^{1}$ Esse texto contou com o apoio e fomento do CNPq, através do Edital Universal 14/2014, para sua realização e consecução.
} 
Entretanto, a proposta inicial das "open universities" evoluiu a passos largos e ganhou um novo significado por ocasião da identificação de novas e diversas possibilidades e estratégias de ensino-aprendizagem que, utilizando dos mesmos meios não-presenciais, acabaram por assumir outro significado. Deste modo, o termo aberta que antes correspondia muito mais a uma certa liberdade de acesso ao ensino é ressemantizado e assume um caráter muito mais pedagógico do que do que democrático de modo que, na atualidade, este refere-se muito mais a todo um conjunto de oportunidades diversificadas de construção do conhecimento fora dos limites da sala de aula do que, uma educação de amplo alcance como em sua proposta original. Modelo este, aceito pela maioria dos estudiosos do tema que na atualidade compartilham tal entendimento conceitual.

Portanto, quando nos referimos a EAD, estamos muito mais nos referindo a essa proposta de um ensino não-presencial baseado em suportes e possibilidades de acesso ao conhecimento diversas do que ao caráter democrático e universal desta como queriam os criadores das primeiras universidades abertas.

Em termos de Brasil a Educação à Distância têm seu início com surgimento da radiodifusão, sobretudo, com a fundação em 1923, da Fundação Roquete Pinto e da Rádio Sociedade do Rio de Janeiro em 1925. À essas primeiras experiências via rádio, seguiram-se as primeiras ofertas de cursos por correspondência que, em 1939, são oferecidos pelo Exército e a Marinha brasileiros aos militares que faziam parte de seus quadros operacionais. Dois anos mais tarde, em 1941, esse mesmo modelo será expandido com a criação do Instituto Universal Brasileiro (IUB) que passou a ofertar a população civil cursos de formação básica e técnica.

$\mathrm{Na}$ época de sua criação em 1941, segundo Iaralham (2009), seu objetivo residia simplesmente em divulgar o curso de contabilidade nas páginas da Revista "O Cruzeiro". Contudo, nos anos seguintes outros cursos foram implantados com especial destaque para os cursos técnicos em eletrônica de Rádio e TV, de Corte e Costura, de Desenho Artístico, de Mecânica de Automóveis e de Auxiliar de Escritório, totalizando até meados dos anos 1950 cerca de 35 cursos. Em 1958, é lançado um curso de Fotografia. E de 1960 a 1980, o Instituto Universal Brasileiro foi praticamente referência em cursos desta modalidade chegando a contar com cerca de 200 mil alunos e dez unidades espalhadas pela cidade de São Paulo.

Contudo, hoje, continua com apenas duas e têm seu foco ligado ao oferecimento de cursos técnicos ligados a área de transações imobiliárias, secretariado e comércio além de outros com foco profissionalizante. Com anúncios e cupom de inscrição publicados em revistas e jornais, o IUB desde meados dos anos de 1940, levava as pessoas cursos dos mais 
diversos que iam daqueles ligados ao Corte e Costura até a Microeletrônica, todos com material e provas enviadas via correio.

Paralelamente ao modelo proposto pela IUB, até o final dos anos de 1990 várias outras experiências e formatos foram testados e levados a efeito com diferentes metodologias: ensino por correspondência, com textos e tarefas pré-programas remetidas ao educando; aulas gravadas em vídeo e transmitidas pela TV ou em fitas domésticas, apoiadas em apostilas e exercícios (como o Telecurso $1^{\circ}$ e $2^{\circ}$ graus da Rede Globo), teleconferências via satélite, etc. Contudo, cabe notar que, o maior impacto na afirmação da EAD se dará a partir da televisão e de sua utilização para fins educacionais.

E será com a oferta em 1969, no estado do Maranhão, pela TV Educativa local, de um curso de $5^{\mathrm{a}}$ a $8^{\mathrm{a}}$ série pela TV, este, apoiado em material didático impresso e monitores que teremos um grande salto na utilização deste suporte. Mais recentemente, seguindo modelo semelhante mas muito mais voltada para atividades e temas relacionados a escola e a conteúdos dos mais diversos é criado o Canal Futura. O qual, via TV a Cabo ganha espaço e através do uso da linguagem jornalística e documental passa oferecer conteúdos e materiais que são, em larga escala, acessados por escolas e pessoas de todo o Brasil que possuem acesso a TV a Cabo.

Com a popularização do acesso a rede mundial de computadores através da redução significativa dos custos de aquisição de equipamentos e do acesso a internet através de provedores de conexão discada gratuitos, e mais tarde com a popularização da banda larga, entre em cena o computador e a comunicação mediada por computador. Relação essa que passará a ser o centro das discussões pedagógicas relativas a EAD, mas não é com o suporte em si e o modo como ele se dá que nos ocuparemos a partir de agora. Mas sim, de como através da comunicação mediada por este suporte, as redes sociais passam a oferecer novas possiblidades pedagógicas a professores e alunos que dela já fazem e/ou podem vir a fazer uso.

\section{EAD HOJE}

Com base nas informações e dados que trouxemos aqui, tem-se que a Educação a Distância, em suas diversas matizes e suportes, não chega a ser efetivamente uma novidade tanto no Brasil quanto no mundo. Mas sim, que trata-se de uma modalidade de ensino que tem uma história construída e resultados observados. Uma modalidade de ensino que tem evoluído e se aproveitado das novas tecnologias e dos recursos de comunicação a essas relacionadas 
para renovar e ampliar sua atuação. Neste processo, mais recentemente, através do uso da internet e das tecnologias digitais, a EAD têm sido impactada de forma significativa na medida em que a Internet traz como novidade a possibilidade de articular recursos e linguagens de diversos meios sobre um mesmo suporte e através de um único canal.

Texto, fotografias, ilustrações, áudio, vídeo, animações são articuladas dentro de um mesmo espaço - a partir de um complexo sistema de hiperlinks - e colocadas a disposição dos usuários/receptores através de diferentes ambientes virtuais de aprendizagem (AVA's). Seu suporte não físico não é mais o papel, a fita K7 ou o VHS, e sim, as telas dos computadores. Bits e bytes tornam-se o simulacro do real e exibem nas telas dos computadores através de novos formatos de áudio (mp3, acc, ogg, wav, midi, etc.), de vídeo (avi, mp4, divx, mov, etc.), de imagem (jpg, png, psd, bmp, etc), de texfo (txt, doc, odt, etc.) e de hipermídia (hml, xhtml, shtml, etc.) conteúdos que são utilizados tanto por alunos quanto por professores no decorrer de seus processos de ensino-aprendizagem.

Neste sentido, é com a redescoberta da EAD a partir do suporte informático e da comunicação mediada por computador que, a exemplo do que se observou na educação presencial, essa, passou a ser considerada como um processo que é, ao mesmo tempo, socialmente mediado e individualmente construído a partir das interações que o sujeito aprendiz constrói no decorrer de sua vida e de suas múltiplas aprendizagens.

Essa noção mostra-se importantíssima para nosso argumento na medida em que coloca o sujeito educando no centro do processo de ensino-aprendizagem independente do meio ou suporte em que isso ocorre. Ou seja, se ressalta que a aprendizagem é um processo contínuo e construído independente da dimensão espaço-tempo presente onde a tecnologia serve como elemento de suporte as atividades e interações grupais necessárias a desenvolvimento do entendimento e aprofundamento dos conhecimentos em foco. Tem-se então que, ao usar do computador como suporte hipermididático a EAD, como já escrevi em outro lugar (MEIRELLES \& BOLL, 2011), diferentemente do que acontecia em outros suportes utilizados, acaba por propiciar uma imersão do indivíduo na paisagem cibernética, produzindo, novas temporalidades e formas de perceber e relacionar-se com o tempo.

Isto posto, e antes mesmo do surgimento do suporte informático, tem-se que a forma como as mais diferentes culturas percebem o tempo e com ele se relacionam é diversa de modo que, o tempo cronológico, da máquina, do relógio, do calendário, assume, um caráter único em cada cultura em função de uma meta-agenda histórico-cultural que valora/desvalora determinados usos e vivências do tempo. Todavia, apesar de passível de uma medição objetiva, esse tempo, a hora de sessenta minutos, pode ser percebida de forma diversa por 
diferentes pessoas que compartilham um mesmo quinhão de 3600 segundos. Disto deriva que, uma mesma hora pode ser mais longa para aquele que estuda matemática e que vê os ponteiros do relógio arrastarem-se rumo a hora fechada do que, a hora vivida por aquele que lê sua revista favorita ou está na praia e vê os ponteiros do relógio correrem de forma frenética rumo ao sexagésimo minuto, parecendo-nos que, essa hora teve muito menos que sessenta minutos.

Curta ou longa, a hora continua a ser do mesmo tamanho e composta por 60 ciclos de 60 segundos, contudo, a forma como esse tempo é percebido é diversa e se relaciona a forma como nós o percebemos e nos relacionamos com ele. E assim, sem dantes nos firmamos em definições conceituais precisas, servimo-nos desses exemplos quotidianos para pensarmos o tempo e a forma como, nós, os modernos, para usar a terminologia empregada por Latour (2000), nos relacionamos com ele e o percebemos em função de diferentes referenciais semânticos que dotam esse tempo de uma temporalidade diversa que deixa de ser o tempomáquina e torna-se o tempo vivido.

Deste modo, para além, do tempo-tempo, do tempo-máquina, tem-se então que a intensidade da experiência está diretamente relacionada ao modo como subjetivamos esse tempo o que, grosso modo, implica em diferentes modos de percebê-lo. E, as redes sociais, simulacro virtual da realidade, acabam por intensificar essa experiência através da forte carga relacional e afetiva que envolve a interação destas e o tempo que, virtualmente, dedicamos aos nossos amigos e parentes que conosco interagem nelas. Assim, ao pensarmos o tempo e a forma como experienciamos ele tem-se que, em termos lexicais, o tempo assume no interior da linguagem, segundo Ricouer (1975), uma diversidade gramatical muito grande que se relaciona ao que poderíamos chamar de uma sintaxe do tempo, ou seja, a forma como esse tempo é utilizado, substantivado, subjetivado por aquele que o toma para si.

Neste sentido, na esteira do exposto por esse mesmo autor, é consenso entre um bom numero de autores, entre os quais destacamos Larre (1975), Panikkar (1975), Baumer (1975), Kagame (1975), Neher (1975), Pattaro (1975) e Gourevitch (1975) que o tempo é, antes de mais nada, um tempo da linguagem, um tempo que se insere naquilo que é vivido no interior de uma determinada cultura, de uma rede de pessoas que interagem entre si e que possuem interesses comuns. Disto decorre que, o tempo vivido, o tempo que estamos em sala de aula, seja esta presencial ou um simulacro dela, é o tempo que vivemos a experiência, é o "nosso tempo" e assume-se, este, quase sempre, como diacrônico e fora do claustro do tempomáquina. 
Esse "nosso tempo" é um tempo com duração perceptiva diversa, é o tempo do sujeito. É o tempo que se sobrepõe no quotidiano da menina-mãe que teve sua infância encerrada precocemente, que estuda, que cuida do filho e da casa, é o tempo do jovem que trabalha para ajudar em casa, que estuda, que faz cursos a distância, que assiste a aula no computador enquanto ouve música, conversa no MSN, interage com amigos no Facebook e olha seus emails. Tudo isso, como diria Arnaldo Antunes, ao mesmo tempo, agora.

Isto posto, tem-se que o tempo vivido pelo indivíduo só é inteligível dentro da cultura e da história que lhe deu origem, da "sua história", da "história da sua comunidade" e a forma como este indivíduo se relaciona com o espaço em que vive e com o tempo, algo que, na antropologia, chamamos de uma etnografia da duração (Eckert \& Rocha, 2000). E, em tempos de redes sociais, esta história, é dotada de sentido na interação deste indivíduo com outros, os quais acabam por formar comunidades de aprendizagem não formais nessas redes.

Isto implica numa mudança de foco na medida em que não há uma observação presente e efetiva das ações e atitudes de cada sujeito naquilo que Gibson (1984) nomina com ciberespaço. No ciberespaço e, consequentemente, nos ambientes virtuais utilizados para fins educacionais ou não, a interação, torna-se a pedra de toque de seu sucesso. E a intensidade da relação e das interações se dará a partir da constituição de redes estreitas ou frouxas (BOTT, 1976) entre aqueles que nessas redes e comunidades interagem. A aprendizagem torna-se coletiva e, o papel do professor e/ou tutor, como mediador desse processo, fundamental.

Ainda nesta direção cabe lembrar que as novas tecnologias de informação e comunicação (NTIC's) ofertam vários recursos e ferramentas de redução da distância. Afinal, estar próximo não significa, necessariamente, estar dividindo um espaço físico, mas sim poder estar interagindo, trocando informações e gerando sentidos entre diferentes sujeitos com um objetivo próximo e comum. O que gera o conhecimento, de forma geral, é a troca de informações entre sujeitos educadores e educandos cujos papéis e atuações se formam dentro de suas especialidades e necessidades e, o uso do computador como suporte, em grande medida, propicia isso.

Pensando em interatividade tem-se que, segundo as correntes mais recentes da teoria da comunicação (WOLF, 2002) podemos dizer que interatividade é a qualidade da interação que se dá no lado da recepção. Claro que esta visão se sustenta nas ações e reações dos sujeitos frente aos meios, os dispositivos tecnológicos que permitem essa comunicação. $\mathrm{O}$ suporte varia, assim como a intensidade e a qualidade dessa interação, independentemente do suporte sobre o qual ela se dá. 
Se olharmos as interações presenciais, vemos que a interatividade é elemento presente, indispensável mesmo ao processo e que, mesmo nesta, onde, o contato físico é o suporte e a base da interação, essa, muitas vezes, pode ser menor que aquela obtida através de outro suporte não presencial quando, por exemplo, alunos apáticos e desmobilizados "apenas ouvem" o professor sem com ele interagir, debater ou questionar, algo não muito incomum nas salas de aula da educação presencial onde, a cada dia que passa, tablets, smartphones e outros dispositivos multimídia ganham cada vez mais espaço.

No contato humano a interatividade se dá e se faz a todo o momento: através da fala, dos gestos, da linguagem corporal, do olhar, da entonação de voz, .... e permite que as pessoas se relacionem, se conheçam e mesmo interpretem suas ações e emoções. Nas redes sociais e na internet, diversas ferramentas buscam cada vez mais simular esse tipo de ação através do suporte cada vez maior a ferramentas de interação instantânea (síncronas) tais como os mensageiros instantâneos (MSN, Gmail, etc.), de chamadas de áudio e vídeo (Skype, TeamViewer, etc.), entre outras. Ou mesmo, tocar a outra pessoa, como é o caso do "chamar a atenção" no caso de alguns mensageiros instantâneos e do "cutucar" no caso do Facebook, por exemplo.

No tocante aos processos de educação esta interatividade se mostra importante na medida em que é possível observar as reações dos diferentes sujeitos frente aos processos, estratégias e atividades adotadas, verificando a validade e mesmo oportunizando lançar mão de novas estratégias para estimular e integrar os educandos aos conteúdos e processos. Ou seja, a interatividade entre educandos e professor-instrutor é indispensável para que a aprendizagem aconteça principalmente se adicionarmos o fato de que as interações entre os educandos nas turmas contribui ao processo. E o uso das redes sociais, pode potencializar esse acompanhamento, uma vez que, como veremos mais adiante, esses alunos, permanecem mais tempo nelas do que conosco, nas salas de aulas presenciais e/ou a distância.

\section{ACESSO ÀS REDES}

As redes sociais são um fenômeno mundial e a cada dia que passa se fazem mais presentes em nossa vida a partir dos mais diferentes suportes como ilustra a imagem abaixo². Em nossa casa através de computadores pessoais e TVs interativas quando não estamos

\footnotetext{
${ }^{2}$ Disponível na web em: http://xkcd.com/256/ por Randall Munroe sob os termos da Licença Creative Commons 2.5 disponível em: http://creativecommons.org/licenses/by-nc/2.5/
} 
falando em mobilidade eles se fazem presentes como suporte de compartilhamento de vídeos, músicas e preferências pessoais.

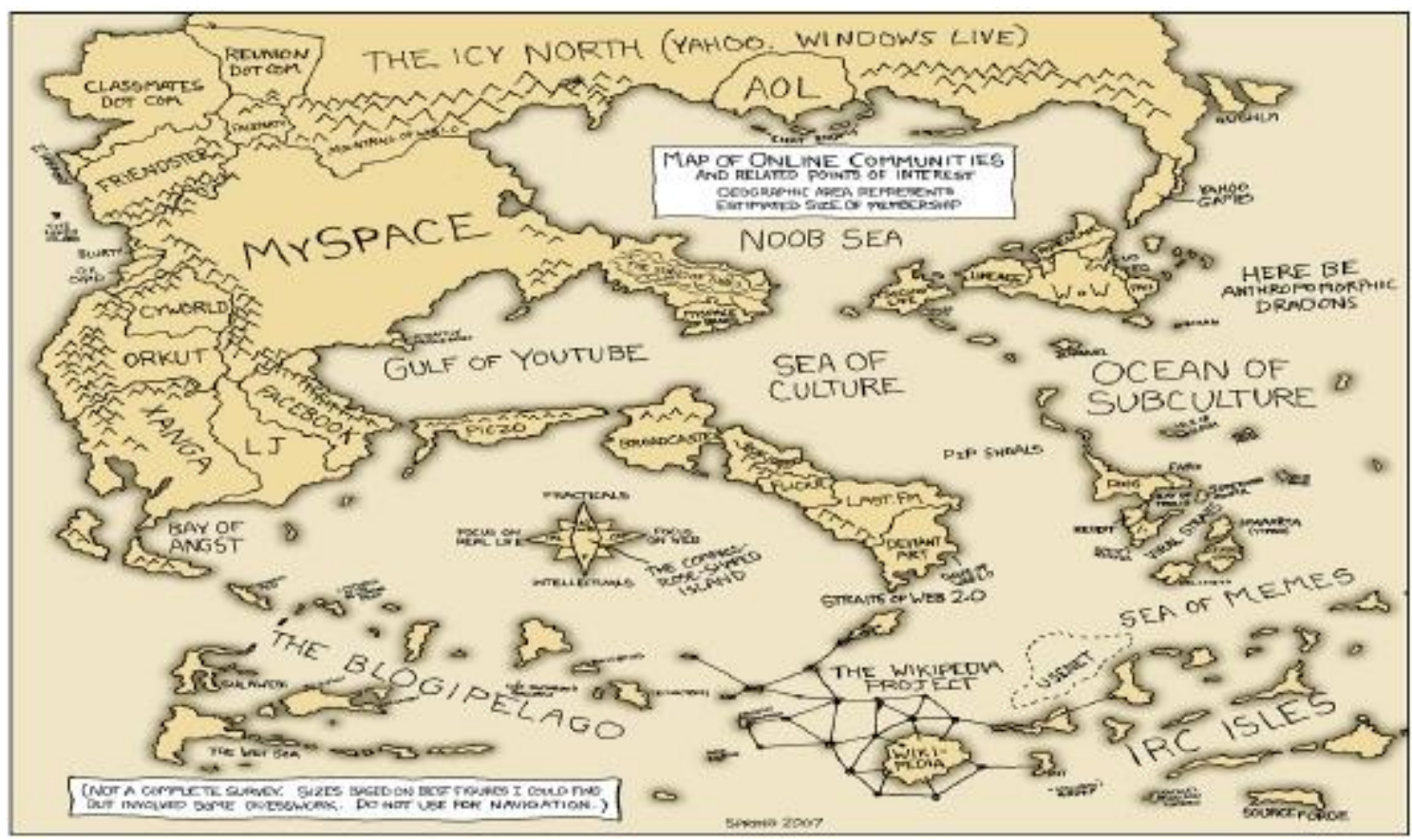

Quando o assunto é mobilidade e redes sociais uma diversidade de dispositivos ganham seu espaço e disputam a preferência dos usuários. Entre esses últimos destacam-se, em ordem de portabilidade, os smartphones, os tablets, os netbooks, os ultrabooks e os notebooks. Aliada a essa portabilidade vertiginosa trazida por esses dispositivos tem-se ainda a popularização das redes wi-fi e das conexões movéis do tipo $2 \mathrm{G}, 3 \mathrm{G}$ e mais recentemente, das possibilidades oferecidas pelas redes $4 \mathrm{G}$, a qual, já é oferecida por algumas operadoras nas principais capitais brasileiras.

Gráfico 1: Distribuição do acesso a rede mundial de computadores em função da velocidade de conexão de acesso do domicílio. 
PROGRAMA DE PÓS-GRADUAÇÃO EM COMUNICAÇÃO DA UNIVERSIDADE FEDERAL DE SANTA MARIA

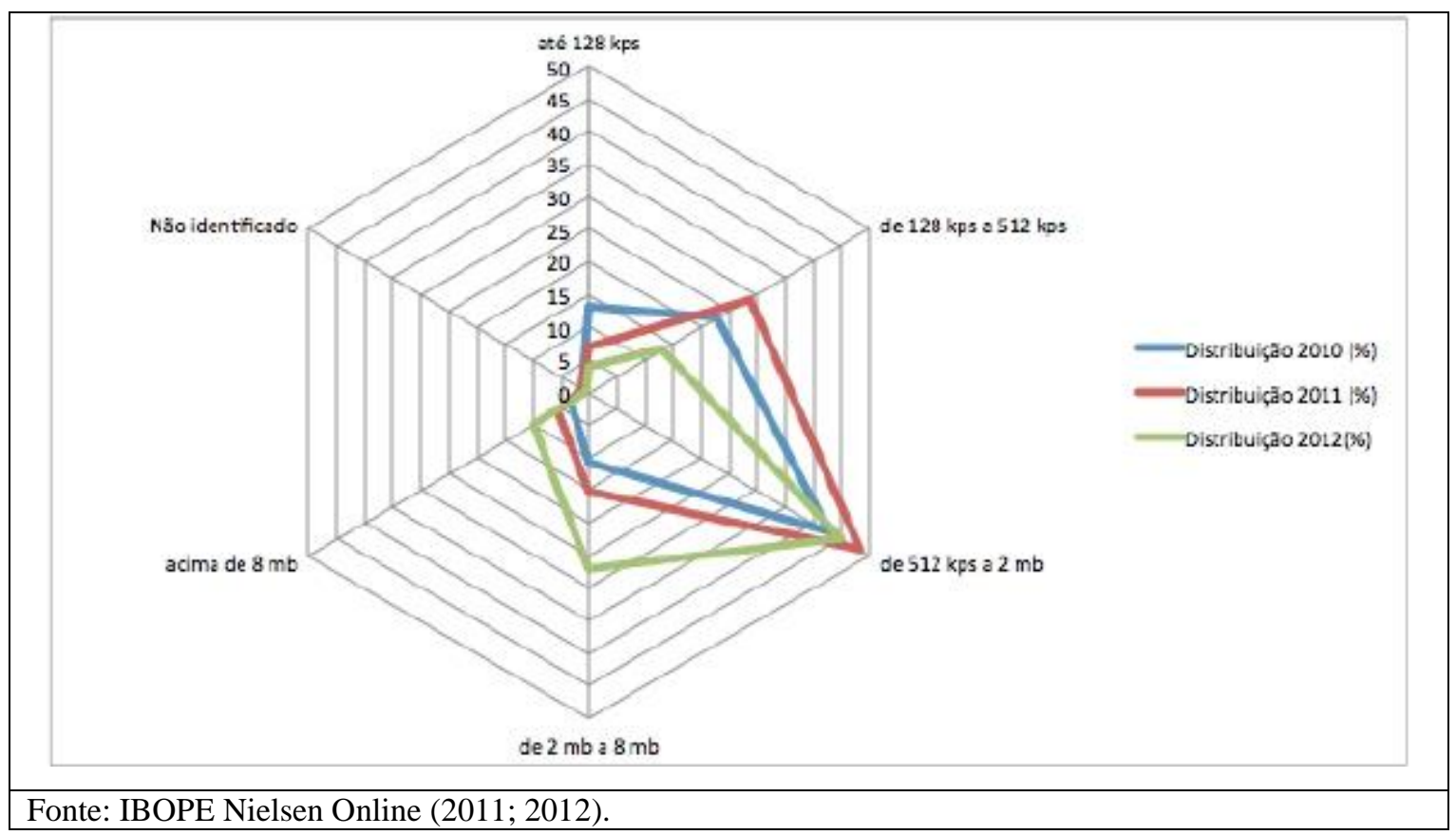

Neste sentido, torna-se praticamente impossível falarmos em redes sociais sem antes nos determos nas possibilidades de conexão existentes no Brasil em termos de acesso a rede mundial de computadores. Neste sentido, dados os padrões de conectividade e acesso a internet existentes tem-se que, hoje, são pelo menos três as possibilidades oferecidas aos usuários brasileiros em ampla escala e a um custo relativamente baixo, a saber: as conexões via telefone (internet discada), via banda larga (cabo e adsl) e as redes móveis ( $2 \mathrm{G}$ e 3G). $\mathrm{Na}$ segunda incluem-se o acesso WI-FI através de hotspots públicos e privados, uma vez que, no caso das conexões via telefone e redes móveis, apesar dessa possibilidade existir, sua viabilidade técnica e a largura de banda disponível oferecida por estes dispositivos, tornam sua utilização praticamente inviável em termos de recursos dispendidos para sua implementação e utilização, seja em pequena ou larga escala.

Isto posto, tem-se que no Brasil, nos últimos anos, o que se observa é um crescimento bastante substantivo no número de usuários de internet banda larga e uma redução significativa no número de conexões discadas, considerando-se nesse caso, para o ano de 2010 um total de 39,9 milhões de usuários no mês de março, para 2011 um total de 43,2 milhões de usuários no mês de março, e, para 2012 um total de 48,7 milhões de usuários em fevereiro deste mesmo ano. Disto depreende-se que o número de acessos em 2012 cresceu 18,7\% em relação a 2010 e, em 13,2\% em relação a 2011. Ainda nesta direção destaca-se que, para o ano de 2012, houve um incremento significativo de usuários que migraram para uma velocidade de banda maior daquela que possuíam em 2010. 
PROGRAMA DE PÓS-GRADUAÇÃO EM COMUNICAÇÃO DA UNIVERSIDADE FEDERAL DE SANTA MARIA

Tabela 1: Tipo de conexão e distribuição de acesso de usuários domiciliares:

\begin{tabular}{lccccccc}
\hline & \multicolumn{2}{c}{$\mathbf{2 0 1 0}$} & \multicolumn{2}{c}{$\mathbf{2 0 1 1}$} & $\mathbf{2 0 1 2}$ & \\
\hline Veloc. conexão & $\boldsymbol{N}$ & $\mathbf{( \% )}$ & $\boldsymbol{N}$ & $\boldsymbol{\%}$ & $\boldsymbol{N}$ & $\boldsymbol{\%}$ & $2010>2012$ \\
\hline até 128 kps & 3863 & 13,3 & 2439 & 7 & 1563 & 4 & $-9,3$ \\
de 128 kps a 512 kps & 7969 & 22,7 & 8432 & 28,7 & 5152 & 13 & $-9,7$ \\
de 512 kps a 2 mb & 12473 & 42,8 & 17005 & 48,4 & 17874 & 45 & 2,2 \\
de 2 mb a 8 mb & 3102 & 10,7 & 5345 & 15,2 & 10781 & 27,1 & 16,4 \\
acima de 8 mb & 941 & 3,2 & 1939 & 5,5 & 3991 & 10 & 6,8 \\
Não identificado & 388 & 1,3 & 428 & 1,2 & 370 & 0,4 & $-0,9$ \\
Total & 35126 & 100 & 29106 & 100 & 39731 & 100 & \\
\hline
\end{tabular}

Fonte: IBOPE Nielsen Online (2011; 2012).

Em especial destaca-se a redução de 9,3\% no número de usuários de conexão discada e o aumento proporcional no número de usuários com conexões de alta velocidade ainda no mesmo período, , como mostra a Tabela 1, os quais apresentam um crescimento de 2,2\% para aqueles com conexões de entrada (de $512 \mathrm{Kps}$ a $2 \mathrm{Mb}$ ), de 16,4 \% para usuários médios (de 2 $\mathrm{Mb}$ a $8 \mathrm{Mb}$ ) e de $6,8 \%$ entre os chamados heavy-users (com conexões acima de $8 \mathrm{Mb}$ ).

Já no que se refere aos padrões de conectividade móvel, como aqueles oferecidos pelas redes WI-FI no caso do uso de hotspots de redes sem fio e das conexões $2 \mathrm{G}$ e $3 \mathrm{G}$ tem-se sua distribuição se dará fundamentalmente no interior do espectro de banda de $128 \mathrm{Kps}$ a $1 \mathrm{Mb}$, variando entre eles, o hardware utilizado, a frequência de transmissão, a capacidade de transferência de dados e o alcance geográfico do sinal de radiofrequência emitido pela estação de rádio-base emissora do sinal, esta, provedora da conexão de acesso móvel. Sendo assim, tem-se que, segundo a Anatel, o Brasil encerrou o mês de março com cerca de 50,9 milhões de celulares baseados na tecnologia 3G, sendo que destes, 43,5 milhões correspondem a aparelhos WCDMA, em especial smartphones, e 7,4 milhões à terminais de dados 3G, estes vinculados ao tráfego de dados via conexões de dados 3G. Lembremos ainda, que este número corresponde a 20,3\% dos celulares 250,8 milhões de celulares ativos no Brasil em março de 2012, ao qual acrescem-se aqueles que se utilizam de tecnologias de acesso $2 \mathrm{G}$ e 2,5G, os quais correspondem a realidade dos outros 200 milhões de usuários que se utilizam de seus aparelhos móveis somente para chamadas de voz e envio de mensagens de texto, ao invés daquilo que se observa entre os usuários de conexões 3G que a utilizam para ter acesso a internet, ver vídeos, ouvir músicas e enviar e receber e-mails.

Em termos gerais, para além das possibilidades oferecidas pelos padrões de conectividade oferecidos pelas redes $2 \mathrm{G}$ e $3 \mathrm{G}$ temos ainda, as redes sem fio, que diferentemente das redes móveis possuem alcance limitado e se utilizam de um padrão de transferência de dados chamado IEEE 802.11, o qual possui diversos protocolos de transferência de dados, entre eles, destacam-se: o 802.11a, o 802.11b, o 802.11g e o 802.11n, 
os quais variam em alcance e capacidade de transferência de dados entre dispositivos, como mostra a tabela a seguir que compara esses padrões.

Tabela 2: Padrões de conectividade 802.11, taxa de transferência de dados, alcance, compatibilidade e custo.

\begin{tabular}{cclll}
\hline Padrão & Taxa de transf. de dados & \multicolumn{1}{c}{ Alcance (indoor) } & \multicolumn{1}{c}{ Compatibilidade } & Custo \\
\hline $\mathbf{8 0 2 . 1 1 a}$ & até $54 \mathrm{Mbit} / \mathrm{s}$ & 25 a 100 metros & Incompatível com b e g & Alto \\
$\mathbf{8 0 2 . 1 1 b}$ & até $11 \mathrm{Mbit} / \mathrm{s}$ & 100 a 150 metros & Incompatível com a e ac & Baixo \\
$\mathbf{8 0 2 . 1 1 g}$ & até $54 \mathrm{Mbit} / \mathrm{s}$ & 100 a 150 metros & Incompatível com a e ac & Baixo \\
$\mathbf{8 0 2 . 1 1 n}$ & até $450 \mathrm{Mbit} / \mathrm{s}$ & até 300 metros & Compatível com a, b e g & Baixo \\
$\mathbf{8 0 2 . 1 1 a c *}$ & Até $1 \mathrm{Gbit} / \mathrm{s}$ & até 300 metros** & Incompatível com b e g & Baixo \\
\hline
\end{tabular}

Fonte: Diversas fontes. Elaboração própria dos autores.

Se compararmos a eficácia e o alcance das redes $2 \mathrm{G}, 3 \mathrm{G}$ e WI-FI tem-se que as tecnologias $3 \mathrm{G}$ permitem às operadoras de telefonia móvel oferecer a seus usuários uma ampla gama dos mais variados serviços ligados a uma maior largura de banda e a uma maior eficiência espectral, entre eles destacam-se a telefonia por voz e a transmissão de dados a longa distância. Neste sentido, ao contrário das redes WI-FI que seguem o padrão IEEE 802.11, as redes $3 \mathrm{G}$ permitem o acesso a internet através de aparelhos de telefonia móvel de longo alcance, em especial smartphones e tablets, e oferecem uma navegação semelhante a que teríamos se estivéssemos usando um PC ou Laptop.

Já as redes $2 \mathrm{G}$, apesar de não oferecerem uma experiência de navegação na internet em alta velocidade, permitem o acesso a rede mundial de computadores a uma velocidade semelhante aquela oferecida pelas conexões discadas (que variam de 14,4 a 56 Kps em função do protocolo utilizado) e através da navegação via texto permite o acesso praticamente global a internet e a sites que oferecem suporte a esse tipo de acesso, como é o caso por exemplo, das redes sociais, e entre elas, especial destaque deve ser dado ao Facebook.

O Facebook, por sua vez, é hoje, a maior rede social do mundo, contabilizando no mês de fevereiro de 2012, cerca de 845 milhões de usuários ativos em todo o mundo. Ainda nesta direção, segundo o site "Social Bakers", o qual mede o tamanho dos países dentro do Facebook a partir do número de usuários ativos mensais, tem-se que, entre os meses de fevereiro e abril de 2012, o Brasil ficou em segundo lugar dentre o número de usuários globais que utilizam a rede de relacionamento criada por Mark Zuckerberg totalizando mais de 46 milhões de usuários, contra 157 milhões dos Estados Unidos que ocupam a liderança isolada e os 45 milhões de usuários ativos da Índia que ocupa o terceiro lugar no ranking do site "Social Bakers". 
PROGRAMA DE PÓS-GRADUAÇÃO EM COMUNICAÇÃO DA UNIVERSIDADE FEDERAL DE SANTA MARIA

Assim, considerando-se o exposto e o fato de que, no mês de março de 2012, segundo o IBOPE Nielsen Online, o Brasil totalizou cerca de 79,9 milhões de pessoas com acesso a internet e que, destas, 66,6 milhões têm seu acesso a partir de seu domicílio e que destes, 48,7 milhões são classificados pelo referido instituto de pesquisa como usuários ativos, há de se considerar que a rede social de Mark Zuckerberg é a preferida por mais de $60 \%$ dos usuários de internet, independente de seu local de acesso. Todavia, dada as políticas de privacidade e de acesso a rede mundial de computadores utilizadas por grande parte das empresas, universidades e estabelecimentos de ensino que bloqueiam o acesso ao Facebook, estima-se que grande parte desse acesso provêm dos domicílios e do uso de plataformas móveis de navegação, o que, dentro de uma estatística bastante conservadora, totalizaria cerca de 80 a $85 \%$ dos usuários ativos.

É de posse destes dados que busca-se no item a seguir pensar a rede social de Mark Zuckerberg como uma ferramenta que pode ser utilizada estrategicamente como forma de potencialização do Ensino à Distância no Brasil.

\section{REDES SOCIAIS E EAD}

O conceito de rede social, por mais obtusa que possa parecer essa afirmação, não é novo e já têm assento nas discussões acadêmicas, pelo menos no campo das ciências sociais em geral e da antropologia em específico desde meados da década de 1950. Sua história vincula-se a um seminário de Manchester que, na década de 50 através de Max Gluckman, deflagrou um levante anti-Radcliffe-Brown que tinha por mote os estudos de redes sociais.

Deste levante teórico, emergirá o trabalho conduzido pelo sociólogo John Barnes intitulado "Class and Committees in a Norwegian Island Parish", publicado em 1954 na revista britânica Human Relations, o qual tinha por mote explicar o modelo de organização social de uma pequena comunidade de Bremer, Noruega, através da análise do conjunto de relações que seus membros possuíam uns com os outros. Sendo assim, será então a Barnes (1954) atribuída a origem do que hoje entendemos por rede social (MITCHELL,1974; LEFEVBRE, 2007; MERCKLE, 2004).

Contudo, sua operacionalização se dará somente mais tarde com os experimentos e estudos de Milgram (1967) e de Bott (1976). Sendo que o estudo do primeiro foi retomado em 2008, pela Microsoft que obteve o resultado de 6,6 graus entre os usuários de seu Instant 
Messenger, e em 2011 em parceria firmada entre o Facebook e o Yahoo ${ }^{3}$ que visa testar a tese dos seis graus de separação ${ }^{4}$. Enquanto que, os estudos de Bott, serviram para delimitar o grau de conexão entre os indivíduos que compõem uma rede, a qual, segundo sua tipologia pode ser entendida em função de seus polos extremos, denominados de malha estreita e malha frouxa. Assim, tem-se que o termo malha estreita é usado para descrever uma rede na qual existem muitas relações entre suas unidades componentes enquanto que, o outro, denominado de malha frouxa é utilizado para designar uma rede na qual os relacionamentos deste tipo ocorrem em menor grau.

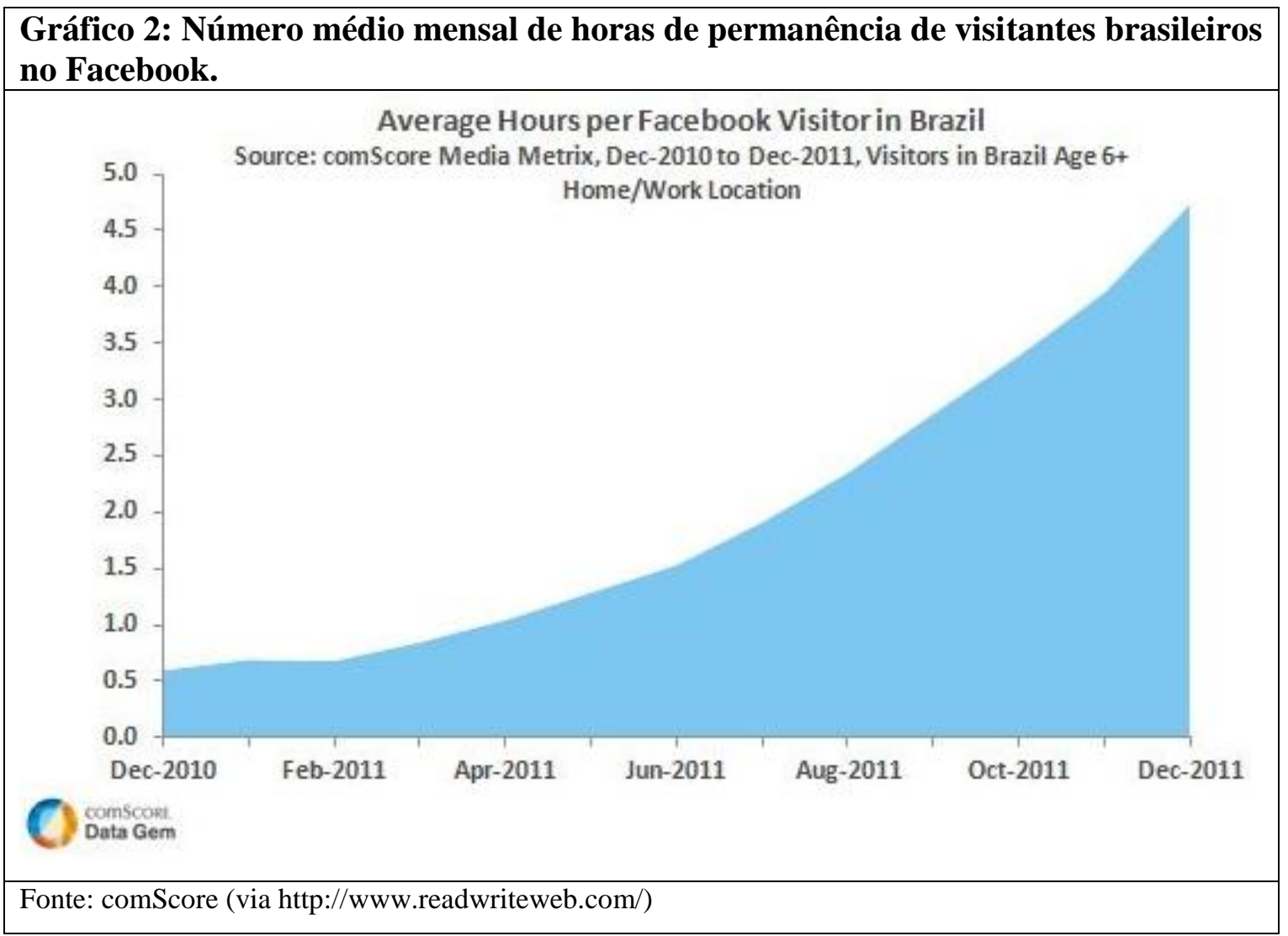

No caso do Facebook e de seu uso educacional interessa destacar o seu uso através da constituição de redes sociais baseadas em malhas estreitas e com grande grau de conexidade entre seus usuários, as quais, ao articularem o uso de computadores e aparelhos de telefonia móvel, podem permitir um grau de interação e resposta bastante satisfatório ao

\footnotetext{
${ }^{3}$ Para maiores detalhes acesse: http://smallworld.sandbox.yahoo.com/index.php?lang=pt\%20

4 No "Small World Problem", Stanley Milgram enviou, aleatoriamente, pacotes a 160 moradores em Wichita, Kansas e Omaha, no Nebraska, pedindo a estes que, após recebê-lo, encaminhasse o pacote a um amigo ou conhecido que eles considerassem que iria enviar o mais rápido possível a um outro indivíduo final, neste caso, um corretor da Bolsa de Valores de Boston, em Massachusetts. De um modo geral, os pacotes chegaram depois de passarem por 5,5 pessoas em média. Contudo, o autor do estudo nunca usou o termo "seis graus de separação", mas esta classificação se tornou lugar comum quando o assunto são redes sociais.
} 
PROGRAMA DE PÓS-GRADUAÇÃO EM COMUNICAÇÃO DA UNIVERSIDADE FEDERAL DE SANTA MARIA

professor - e, também, entre o corpo discente - na medida em que se utiliza de uma "plataforma de interação" bastante comum entre o público jovem. Neste sentido, segundo dados divulgados pelo Cetic.br em 2011, há de se destacar que, em 51\% dos domicílios pesquisados, as crianças já haviam usado um computador e que, dentre estes, 27\% declaram já ter usado a internet. Ainda nesta direção destaca-se na pesquisa o fato que $90 \%$ das crianças de 5 a 9 anos o fizeram com vistas a acessar jogos online, e ainda que, entre elas $45 \%$ utilizou a rede para busca de informações para a escola, ao mesmo tempo em que, 29\% delas afirmava usar o Facebook e/ou Orkut, além do fato de, $25 \%$ destas afirmarem que trocavam mensagens instantâneas usando Instant Messengers (IM) e, também, em 10\% dos casos através do uso de ferramentas de e-mail.

Em termos de dispêndio de tempo nas redes sociais tem-se que, em agosto de 2010, o usuário médio do Orkut permanecia em média 275 minutos no referido site, enquanto que, no Facebook esse tempo de permanência mensal no mesmo era quase dez vezes menor, totalizando 29,3 minutos. Um ano depois, o Orkut praticamente está morto e numa tentativa desesperada de recuperar os seus usuários a Google lança o Google Plus, mas já e tarde, uma vez que, o tempo médio de permanência do usuário no Facebook totalizava, em dezembro de 2011, 288 minutos (ou 4,8 horas).

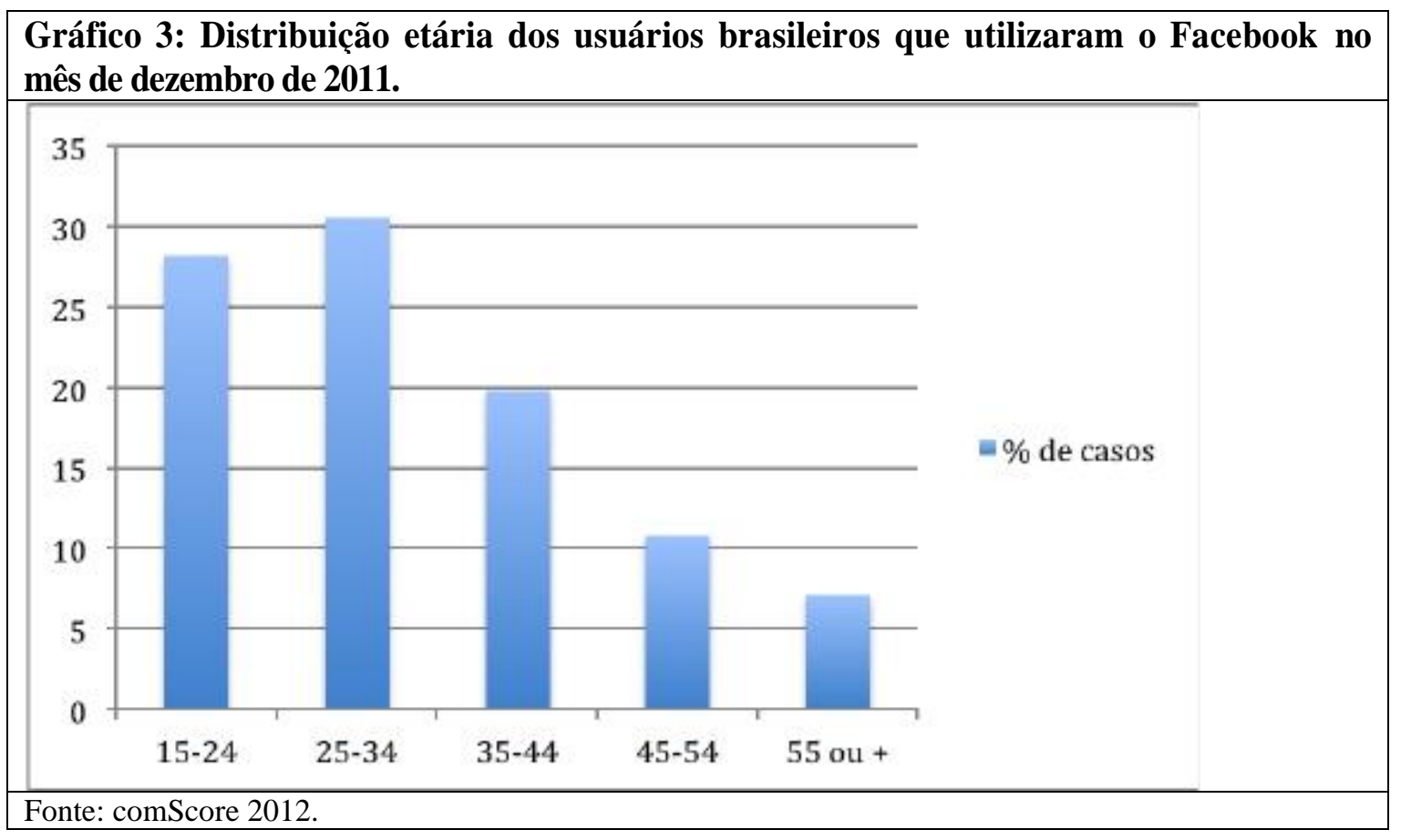

Ainda nesta direção, é interessante, também, o perfil dos usuários do Facebook em dezembro de 2011, os quais, segundo a comScore se distribuíam de forma equitativa entre os 
PROGRAMA DE PÓS-GRADUAÇÃO EM COMUNICAÇÃO DA UNIVERSIDADE FEDERAL DE SANTA MARIA

sexos masculino $(49,1 \%)$ e feminino $(50,9 \%)$. Contudo, o tempo de navegação no mesmo era maior entre as mulheres (em média 1,2 horas a mais que os homens) e a concentração etária inferior a 25 anos, como vimos no gráfico 3.

\section{FACEBOOK: REDES SOCIAIS E EDUCAÇÃO, POSSIBILIDADES} AUMENTADAS?

Isto posto, passemos a algumas possibilidades que o Facebook pode oferecer aos educadores e professores interessados no uso das plataformas sociais em suas aulas. Sobretudo, consideremos nossa "ClassRoom no Facebook" como dotada de uma malha estreita, onde, existe um identidade comum entre seus membros que se vinculam a um “Turma” e que, dentre estes, existem laços afetivos, de amizade e de interesse.

Desde meados de 2010 começou a surgir na rede mundial de computadores uma série de postagens em blogs educacionais e de artigos científicos que buscavam explorar as possibilidades oferecidas pelas redes sociais e, desta forma, inaugurou-se um novo campo de estudos na educação que se assenta na relação entre as redes sociais e a educação. Recentemente, com o avanço dos estudos no campo da linguística e, mais especificamente, da sociolinguística, a ideia de malha estreita e malha frouxa de Bott (1976) dá lugar a noção de redes de alta e baixa intensidade, noção esta, tributária a Coates (1993).

Sua caracterização, por sua vez, apesar de retomada de forma um pouco diversa de sua acepção tradicional não difere em muito do modelo proposto por Bott e se assenta, também, na interligação e no grau de interatividade daqueles que compõem essas redes, sendo nominadas, a partir disso como abertas ou fechadas (TUZINE, 1997). Interessa-nos aqui, as redes de alta intensidade, onde, a norma é reforçada a partir da interação entre aqueles que a compõem (DURKHEIM, 2007; FOUCAULT, 2004; BOURDIEU, 2007).

Parte-se então, a priori, que a adoção de um modelo de ensino baseado em redes sociais deve estar, de certa forma, circunscrito a um dado grupo de alunos. Tal grupo, no plano ideal, compor-se-á, portanto, por alunos de um dada turma que, num dado momento do tempo, interagem com um professor. Contudo, dado o caráter extremamente capilar das redes sociais, é preciso que, nas redes sociais, nos utilizemos de dois recursos já conhecidos há mais de vinte anos entre os entusiastas da Educação à Distância, quais sejam, as comunidades virtuais de aprendizagem e os fóruns de discussão, aos quais, pode-se aliar também um mensageiro instantâneo que permita a comunicação entre aqueles que compõem o grupo. 
Em resposta a essas necessidades emergentes e de olho nas possibilidades oferecidas pelas redes sociais Philips, Baird \& Fogg (2011) lançaram junto a própria rede social que dá nome a esse item um breve "Guia do Usuário", onde, os referidos autores colocam em evidência o modo como o Facebook pode ser utilizado como uma ferramenta que pode auxiliar o professor no processo de ensino e aprendizagem dos alunos tanto em sala de aula como fora dela. Nesse sentido, considerando o exposto no Gráfico 2 e o tempo de permanência na referida rede social tem-se que, na prática, os alunos que hoje fazem parte de nossas salas de aula, passam um tempo no mínimo igual ou superior aquele que estão conosco em sala de aula de modo que

In many cases students spend as much (or more) time online in an informal learning environment--interacting with peers and receiving feedback--than they do with their teachers in the traditional classroom (PHILIPS, BAIRD \& FOGG, 2011: 3). ${ }^{5}$

Assim, tem-se que, após criarmos uma conta no Facebook, teremos acesso a quatro elementos básicos que compõem a rede social, quais sejam, a nossa página inicial, o nosso perfil, os nossos grupos e as nossas páginas. Nos interessa aqui, somente os dois últimos itens e o mensageiro on-line que compõem a plataforma da referida rede social. E, sem inaugurarmos novos conceitos, pensemos a função "grupos" como atrelada a ideia de comunidade virtual e fórum, ao mesmo tempo em que, a função "páginas" ocupará o lugar daquilo que poderíamos chamar de mural.

$\mathrm{Na}$ prática, enquanto simulacro do real o que estaremos fazendo ao usar essas duas funções é criar uma sala de aula virtual (ou grupo, o qual poderá se restringir somente aos nossos alunos ou a outros) onde se produzirá a interação assíncrona (através de postagens, compartilhamentos e comentários) e síncrona (através do mensageiro padrão, o qual também pode ser configurado pelo professor para permitir acesso somente aqueles que fazem parte do grupo). O conteúdo a ser discutido (e distribuído para o grupo) se dará, por sua vez, através da página do grupo que, tanto o professor como o aluno terão acesso imediato através dos feeds e postagens que se farão presentes em sua linha do tempo.

Desse modo, após a distribuição de um conteúdo ou material específico ao grupo através da página do mesmo, o professor pode acompanhar as discussões, acrescentar materiais, fazer comentários, promover debates, sem a necessidade de se utilizar de uma plataforma educacional específica, uma vez que, dada a rigidez e o desenho instrucional pouco

\footnotetext{
${ }^{5}$ Em muitos casos, os alunos passam tempo on-line tanto (ou mais) em um ambiente de aprendizagem informal interagindo com os colegas e receber feedback - que eles fazem com seus professores em sala de aula tradicional
} 
atrativo da maioria dos ambientes de aprendizagem a distância, esse, acaba sendo um fator de resistência a sua utilização tanto por parte do professor quanto do aluno em função de sua usabilidade (KUNTZ, 2010). Ainda nesta direção é importante destacar que quando alguém curte uma página (FanPage) ele passa automaticamente a receber na sua linha do tempo as atualizações feitas na mesma de modo que, para além do tempo e espaço circunscrito do ano letivo, esse aprendizado pode continuar se dando ao longo de toda a vida.

E da mesma forma que, quando falamos de mobilidade e das plataformas móveis de acesso a internet que permitem a um grande número de pessoas interagir na referida rede social, tem-se que, tal portabilidade acaba por gerar uma nova forma de relacionar-se com o tempo, o espaço e o aprendizado escolar como já escrevi em outro lugar (MEIRELLES \& BOLL, 2011). E deste modo, a partir da página de uma disciplina qualquer (FanPage) acabamse por criar-se, dada a forma como os jovens interagem e se utilizam da tecnologia, redes de aprendizagem e colaboração pessoais que se assentam naquilo que nominamos comumente como comunidades virtuais de aprendizagem.

Há de considera-se então que, para além do atual avanço obtido em termos de interface e usabilidade no que se refere ao atual estágio de desenvolvimento da maioria dos ambientes virtuais de aprendizagem, as redes sociais representam uma nova possibilidade que extrapola os limites circunscritos da aprendizagem formal, esta, inscrita no espaço escolar strictu sensu e em seus simulacros virtuais materializados numa infinidade de ambientes educacionais de aprendizagem, hoje, disponíveis no mercado.

E, deste modo, para além do espaço escolar, as redes sociais, dadas suas especificidades e a forma como se organizam e estruturam, acabam por alargar o espaço da escola, dos ambientes virtuais de aprendizagem e a forma como o conhecimento é produzido e compartilhado entre as gerações mais novas que têm a rede mundial de computadores como seu lócus privilegiado de interação.

\section{CONSIDERAÇÕES FINAIS}

Observando brevemente por outro viés, um estudo realizado pelo antropólogo Julian Orr (AGRE, 1999) observou que os empregados de uma empresa de manutenção de copiadoras desenvolviam suas capacidades técnicas menos nos treinamentos e muito mais nos horários após expediente quando, reunidos com os colegas, bebiam e trocavam "histórias de guerra”. Neste ambiente foi introduzida, para uso dos técnicos, uma central de telefonia móvel 
totalmente livre e sem controle, de forma que os técnicos pudessem falar entre si a qualquer momento.

Por outro lado, Agre (1999) também mostra que, em uma empresa de contabilidade global foi feito enorme investimento em tecnologia informática, colocando computadores, servidores, softwares e tudo aquilo que era necessário para que os funcionários trocassem informações instantaneamente. Entretanto, tal sistema não era utilizado devido a forte concorrência entre estes, onde, qualquer pequena informação era utilizada para superar a pessoa ao lado e subir de posto. A partir disso, o referido autor conclui que a tecnologia não é substituta de uma boa relação física, no mundo real, mas sim, um meio complementar de troca entre as pessoas de uma rede ou grupo já bem organizado e estruturado.

Frente a isto, e dado o exposto até aqui, considerando-se um certo conjunto de experiências já existentes acerca da utilização das redes sociais na educação e em outras áreas do conhecimento pode-se dizer que, ao que parece, elas vieram para ficar. E em razão de sua quase onipresença em nossa vida através de dispositivos móveis e fixos tais como celulares, notebooks, tablets, computadores pessoais, televisores e até vitrines de lojas interativas como é caso da loja da Billabong, conhecida grife de surfe, instalada no shopping Center Iguatemi, em Alphavile, São Paulo - que tal suporte não pode ser desconsiderado.

Alie-se a isso, o tempo de permanência e utilização destas plataformas pelos jovens e ver-se-á que, por mais que não se queira aceitar essa realidade, as estatísticas de acesso mostram que estamos andando por um estrada de mão única, onde, a palavra-passe é interação. Mas não qualquer interação e sim, interação em rede, e que cada vez mais, as redes sociais substituem formas tradicionais de sociabilidade através da utilização de álbuns de fotografias virtuais que substituem seu congênere físico, de diários que agora são feitos online e marcados na linha do tempo através da realização de check in online e de postagens, entre outros.

Sendo assim, o presente texto buscou pensar essa realidade e explorar essa nova topografia do real que, através do uso das redes sociais, ganha cada vez mais espaço em nossas vidas. Disto depreende-se que, diferentemente de outrora, no caso das redes sociais já há, entre a maioria dos jovens, dadas suas condições de acesso a rede mundial de computadores e modo como com elas interagem, uma cultura digital latente que, nós, professores e pesquisadores precisamos explorar melhor com vistas a agregar valor a nossas aulas sem ter que lutar - como em tempos outros - com a resistência ao uso desse suporte pelo corpo discente. E assim, antes de propor-se novos termos e conceitos, devemos reinventar nossas práticas e trazer toda nossa experiência com o uso dos AVAs para o interior das redes 
sociais, ressignificando-as enquanto um lócus ampliado onde a educação também pode (e deve) se fazer presente.

As redes sociais podem ser a nova $M e c a$ da Educação à Distância, onde, o professor, apropriando-se dos recursos ofertados pelas diferentes redes disponíveis e criando ambientes com recursos próprios destas redes pode potencializar as relações de troca, ampliando, assim, o alcance das relações existentes e aprofundando a construção dos saberes não só durante as aulas, mas sim, para toda a vida.

\section{REFERÊNCIAS}

BARNES, J. A. Class and Committees in a Norwegian Island Parish. Human Relations. London, n. 7, p. 39-58, 1954.

BAUMER, B. Apêndice: A percepção empírica do tempo. In: RICOUER, P. (Org.) As Culturas e o tempo: estudos reunidos pela Unesco. Petrópolis: Vozes; São Paulo: Editora da USP, 1975, p. 95-101.

BOTT, E. Família e rede social. Rio de Janeiro: Francisco Alves Editor, 1976.

BOURDIEU, P. O poder simbólico. Rio de Janeiro: Bertrand Brasil, 2007

COATES, J. Women, Men and Language. London: Longman Group UK Limited, 1993.

DURKHEIM, E. As regras do método sociológico. São Paulo: Martins Fontes, 2007.

ECKERT, C.; ROCHA, A. L. C. "Imagens do tempo nos meandros da memória: por uma etnografia da duração”. Revista Iluminuras, V.1, n.1. Porto Alegre: UFRGS/PPGAS, p. 1-14, 2000 .

FOUCAULT, M. Vigiar e punir: nascimento da prisão. Petrópolis: Vozes, 2004.

GIBSON, W. Neuromancer. São Paulo: Aleph, 1984.

GOUREVITCH, A. Y. O Tempo como problema de história cultural. In: RICOUER, P. (Org.) As Culturas e o tempo: estudos reunidos pela Unesco. Petrópolis: Vozes; São Paulo: Editora da USP, 1975, p. 263-283.

KAGAME, A. A percepção empírica do tempo e a concepção da história no pensamento bantu. In: RICOUER, P. (Org.) As Culturas e o tempo: estudos reunidos pela Unesco. Petrópolis: Vozes; São Paulo: Editora da USP, 1975, p. 102- 135.

KUNTZ, V. H. O design da interface com facilitador ao professor na utilização de ambientes virtuais de aprendizagem. Curitiba: PPD/UFPR, 2010. 185p. Dissertação de Mestrado. 
IARALHAM, L. C. Contribuição da tecnologia da informação na educação a distância no instituto universal brasileiro: um estudo de caso. Revista Científica da Faculdade das Américas, Ano III, n.1, 1o sem. 2009.

LARRE, C. A percepção empírica do tempo e a concepção da história no pensamento chinês. In: RICOUER, P. (Org.) As Culturas e o tempo: estudos reunidos pela Unesco. Petrópolis: Vozes; São Paulo: Editora da USP, 1975, p. 41-72.

LATOUR, B. Jamais Fomos Modernos. Rio de Janeiro: Editora 34, 2000.

LEFEVBRE, A. Les réseaux sociaux - pivot de l'internet 2.0. Paris: M2 Editions, 2007.

MEIRELLES; M.; BOLL, C. I. Sobre o tempo que passou: a imersão na paisagem cibernética e o surgimento de novas temporalidades e formas de perceber o tempo. RENOTE - Revista Novas Tecnologias na Educação. Porto Alegre, v. 9, n. 2, p. 1-10, 2011.

MERCKLE, P. Sociologie des réseaux sociaux. Paris: La Découverte, 2004.

MILGRAM, S. The Small World Problem. Psychology Today. New York, v. 1, n. 1, p. 61-67, 1967.

MITCHELL, J. C. Social Networks. Annual Review of Anthropology. V.1. n. 3, p. 279-299, 1974.

NEHER, A. Visão do tempo e da história na cultura judaica. In: RICOUER, P. (Org.) As Culturas e o tempo: estudos reunidos pela Unesco. Petrópolis: Vozes; São Paulo: Editora da USP, 1975, p. 176-196.

PANIKKAR, R. Tempo e História na tradição da Índia. In: RICOUER, P. (Org.) As Culturas e o tempo: estudos reunidos pela Unesco. Petrópolis: Vozes; São Paulo: Editora da USP, 1975, p. 73-94.

PATTARO, G. A concepção cristã do tempo. In: RICOUER, P. (Org.) As Culturas e o tempo: estudos reunidos pela Unesco. Petrópolis: Vozes; São Paulo: Editora da USP, 1975, p. 197-228.

PHILIPS, L. F.; BAIRD, D.; FOGG, B. J. Facebook for educators. 2011.

RICOEUR, P. "Introdução". In: RICOUER, P. (Org.) As Culturas e o tempo: estudos reunidos pela Unesco. Petrópolis: Vozes; São Paulo: Editora da USP, 1975, p. 15-40.

TUZINE, A. O Papel da rede social na variação e mudança linguística. In: STROUD, C.; GONÇALVES, P. (Orgs.). Panorama do português oral de Maputo (Volume 1). Maputo: Stockholm Institute of Education, 1997. p. 75-100.

WOLF, M. Teorias das Comunicações de de Massas. São Paulo: Martins Fontes, 1999.

\section{DOCUMENTOS NA WEB:}

Apenas $10 \%$ dos usuários móveis respondem por $90 \%$ do tráfego global. IDG Now, São Paulo, jan. 2012. Disponível em: http://migre.me/8YQLP. Acesso em: 20 abr. 2012. 
Brasil com 50,9 milhões de celulares 3G em Março de 2012. Teleco, São José dos Campos, abr. 2012. Disponível em: http://www.teleco.com.br/3g_brasil.asp. Acesso em: 3 mai. 2012.

Congratulations To Brazil: The 2nd Biggest Country On Facebook! Social Bakers, mai. 2012. Disponível em: http://migre.me/8YQRb. Acesso em: 5 mai. 2012.

Estatísticas de Celulares no Brasil. Teleco, São José dos Campos, abr. 2012. Disponível em: http://www.teleco.com.br/ncel.asp. Acesso em: 3 mai. 2012.

Facebook Blasts into Top Position in Brazilian Social Networking Market Following Year of Tremendous Growth. comScore, New York, jan. 2012. Disponível em:

http://migre.me/8YQJp. Acesso em: 3 mai. 2012.

Número de brasileiros com acesso a internet chega a 79,9 milhões. IBOPE Nielsen Online, São Paulo, abr. 2012. Disponível em: http://migre.me/8YQHr. Acesso em: 3 mai. 2012.

Número de usuários ativos cresceu 13,9\% em um ano. IBOPE Nielsen Online, São Paulo, mai. 2011. Disponível em: http://migre.me/8YQGv. Acesso em: 3 mai. 2012.

Somente $27 \%$ das crianças entre 05 e 09 anos acessaram a Internet no Brasil. Convergência Digital, São Paulo, out. 2011. Disponível em: http://migre.me/8YQKd. Acesso em: 3 mai. 2012.

Original recebido em: 31/03/2013

Aceito para publicação em: 18/02/2016

Mauro Meirelles

É Licenciado em Ciências Sociais (UFRGS), Mestre em Educação (UFRGS) e Doutor em Antropologia (UFRGS). Atualmente é professor do Curso de Graduação em História e do Mestrado em Memória Social e Bens Culturais da Unilasalle/Canoas.

César Steffen

Doutor em Comunicação Social formado pela FAMECOS/PUCRS em 2010. Possui graduação em Comunicação Social - Publicidade e Propaganda pela UFRGS (1997), mestrado em Ciências da Comunicação pela UNISINOS (2004) e é especialista em Educação à Distância (2008). Possui três livros e vários artigos publicados no Brasil e exterior. É docente nas áreas de Comunicação Social e Administração - Marketing, e consultor de empresas nas áreas de marketing, internet, comunicação, publicidade e administração. Atua junto ao mestrado em "Memória Social e Bens Culturais" e aos cursos de Administração e de Marketing do UNILASALLE - Canoas/RS. É pesquisador CNPq, com projeto de pesquisa sobre economia criativa em andamento.

Esta obra está licenciada sob uma Licença Creative Commons. 